\title{
Dynamic Analysis of Language Function from the Perspective of Sociolinguistics
}

\author{
Dawa Pengcuo ${ }^{1,2, *}$ Fu Zhang ${ }^{1,2}$
}

\author{
${ }^{1}$ Key Laboratory of China's Ethnic Languages and Information Technology of Ministry of Education, Northwest \\ Minzu University, Lanzhou, Gansu 730030, China \\ ${ }^{2}$ Department of Chinese Language and Literature, Northwest Minzu University, Lanzhou, Gansu 730030, China \\ "Corresponding author. Email: 526959649@qq.com
}

\begin{abstract}
As a special phenomenon of human society, language is always accompanied with human beings. And it has always been in a dynamic and open ecosystem. It gives us a lot of inspiration. We must observe and discuss the interrelation and mutual influence between language and its surrounding environment as well as social reality while studying language. In view of this, this paper adopts the method of comparative analysis, and focuses on three aspects from the perspective of sociolinguistics, which include language learning and national identity as well as individual identity, language vision and language planning, the promotion of Mandarin and the protection of endangered languages. And finally it comes to the conclusion. Language has the dual functions of national identity and individual identity. There is no fundamental conflict between the promotion of mandarin and the protection of minority languages in China. China's language policy and language planning should be based on China's national conditions. We should not only consider China's needs of current economic, political, and cultural development, but also combine its goals of long-term development and the individual future development.
\end{abstract}

Keywords: language learning, national identity, individual identity, language planning, promotion of mandarin, language protection

\section{INTRODUCTION}

Globalization is a social phenomenon. In the comprehensive process of global economic, political, technological and cultural integration, the language phenomenon is also more complex and diversified than ever before. As the most important communication tool of human, language comes into being with the emergence of human beings. It plays a very important role in the transformation from natural human to social human. Just as water is to fish, so air is to man. Language is absolutely indispensable to the development of human society and real life. Thus, humans have studied their language for a long time. In the study of language, they pay special attention to the problems being related to language application, such as bilingual teaching, language contact, language substitution as well as usage of new words and expressions. As a typical social phenomenon, language is always accompanied with human beings. It is also a dynamic and open system. Therefore, we should not only study abstract objects, but also make reasonable explanations for various language phenomena. Without colorful social reality, to study language is one-sided. We must combine language with society. It is necessary and feasible to put language study in the dynamic context of social life. With the help of the approach, we can broaden the field of language research, and build a bridge between diachronic and synchronic research, combining quantitative with qualitative research as well as static with dynamic research.

\section{LANGUAGE TEACHING \& NATIONAL AND PERSONAL IDENTITY}

\section{A. Language learning and national identity}

"A stable community of language, region, economic life and psychological quality reflected through culture in common is formed in human history".[1] This is Stalin's definition of what a nation is. From his words, we can understand that language plays a primary role in national identity among the four elements (language, region, economy and culture) that constitute a nation. As 
we know, language has two basic functions: one is social function, and the other thinking. The function of thinking is usually the indirect and general reflection of people on objective things. Taking kinship terms between English and Chinese as an example, uncle in English refers to "bo fu" (伯父), "gu fu" (姑父), "yi fu" (姨夫) and so on in Chinese, and aunt corresponds to "bo mu" (伯母), "gu gu" (姑 姑), "yi mu" (姨母), etc. Similar examples can be found among the two languages easily. It shows that a language embodies a way of thinking. Language and thinking are inseparable. This example also reflects psychological cognitive problems behind language. For people who speak the same language, they have the same mental cognition on objective things. To a certain extent, speaking a certain language already shows its distinct national characteristics. It can be imagined that if the language of a nation disappeared the nation would exist only in name actually. We often see one familiar example that the first thing they did was to force Indians to learn English after British conquered India by force of arms. "We need a group of Indians by birth and color of skin, but the British among their hobbies, opinions, morals and knowledge",[2] which is their language policy Lord Macaulay being in charge of education in India in 1835 described. There's no doubt that the main motive of this practice is to achieve the goal of destroying the nation with the method of destroying language.

\section{B. Language learning and individual identity}

To a certain extent, language directly or indirectly reflects the national characteristics of a nationality. The national brand has been deeply engraved on her language. Today the wave of globalization has swept the whole world. It's increasing communications and interactions of people from different countries, and making people much more concerned about their identities than ever before. As human beings, each of us can't change or choose our skin color, weight, height and appearance. Because these physical characteristics are innate. However, language makes people's identity changeable. Harrison (1998) argues that individual identity can be created through culture, especially through language, which is the easiest and most effective way to identify others and show your own identity.[3] "Non-Greek" are defined as people who speak words they couldn't understand and referred to as "barbarians" by the Ancient Greeks. Because strings of their sounds like "barbarbar" mean nothing to the Greeks. Therefore, some people have vividly described the function of their mother tongue as a barrier to the outside, but a binder to the inside.

Language makes people's identity changeable. For individuals, we have learnt and mastered a language, which means that we also gain an identity. For example, if an Asian can speak Chinese, Japanese and Korean, he can easily gain language identity among China, Japan and Korea. In view of the above-mentioned fact, in order to catch up with the step of modern life, people have to reduce their time being spent on learning their own national language and energy. It's a universal problem that people of many countries are facing in the world. For the purpose of speeding up the international integration, foreign language fever quietly emerged in China in the second half of the last century. We know that language and culture are linked inextricably. Learning a language is learning a culture to some extent. Accordingly, learning a foreign language requires understanding and accepting a certain amount of western culture. With the increasing rate of foreign language, and the cultural shift of foreign language teaching, there are more and more calls for strengthening culture of foreign language in foreign language teaching. We should pay our attention to these phenomena. In theory, as a part of the language and cultural education, the education of foreign language will affect the national language and cultural identity in different ways, to a greater or lesser degree. Behind the identity of language and culture is the individual identity.

It is true that mastering culture and knowledge of foreign language contributes to proper communication in cross-cultural communication and promotes understanding and mutual trust between different national cultures. At the same time, we also need to take a more cautious attitude towards foreign culture, and identify them. Because foreign nationality, outlook on life, value, religious view, ethics, morality and political leanings may not adapt to China's national conditions. If we allow foreign language education to run its course, and don't identify its content, and let it spread its culture at will, the spiritual world of foreign language learners in China will be seriously affected. Then it will have some impacts on the identity of language and culture of China, which will result in the metamorphosis or loss of national identity. In contemporary China, education of foreign language is multilingual and multicultural. The impacts of different languages and cultural education on the culture of national mother tongue and identity remain to be assessed objectively and fairly. Therefore, the education of foreign language in China deserves our attention, against the current background of internationalization and globalization. And how to properly deal with foreign cultural education is also crucial. 


\section{LANGUAGE VISION AND LANGUAGE PLANNING}

\section{A. A brief description of language planning}

There is nothing being stationary in the world. Everything is constantly evolving. As the most important tool of human communication, language is also the same. It's changing all the time. Because language changes slowly, it is not easily noticed by people. As time went on, these subtle and imperceptible changes produced some significant differences of language. At the same time, in order to attract others' attention, some people often try to say some novel words in daily communication, which will also cause changes of our language and vocabularies. Among these changing phenomena of language, some of them conform to the general law of language development, and some don't. Based on the above consideration, in the light of the phenomena appeared in the processes of language development and changes, we need to consider and choose the expressions which conform to the law of language development and is conducive to communication at the same time, then confirm and promote them. And for those usages which don't conform to the law of language development, we need specification and properly handle them.

From the above elaboration, we can see that the purpose of language planning is to serve the society better by means of solving various problems in the process of language communication. And the government or social groups can carry out many kinds of activities of regulation and management on language and its usage with plans, aims and organization. Language planning in China can be traced back to the Qin Dynasty. Among the various laws and policies of it, the policy of "book with text", as we all know, was a very important measure for language planning. Subsequently, the various dynasties in Chinese history also regulated the use of language in various ways, such as advocating, making explicit provisions and issuing relevant decrees, etc., promoting the work of language. After the founding of the People's Republic of China, consideration of national development and social progress, the state put the emphasis on language and its use, and formulated and issued a series of policies and regulations on language, and made some achievements. Entering the new period, with the deepening of reform and opening up, China's politics, economy, culture, science and technology are also accelerating, the society urgently requires to strengthen the standardization and sorting of the language in the new period.

\section{B. Classification of language planning}

At present, the academic community usually divides language planning into two categories[4]: one is status planning, which aims to enhance the role and influence of a certain language in national politics, economy, culture and people's daily life, and to ensure its core status of social communication. For example, China confirms the social communicative status of Mandarin and standardized Chinese characters in the form of law. The Law of the People's Republic of China on The Standard Spoken and Written Chinese language stipulates that Mandarin and standardized Chinese characters are the common language of China. The second is ontology planning, which is mainly carried out around the ontology of a certain language, involving the promotion and standardization of common language, the formulation of norms and standards of text, and the standardization of scientific and technological terms. Ontology programming mainly focuses on two disciplines, sociolinguistics and applied linguistics.

\section{Language planning from the perspective of linguistics}

1) Processing of loanwords: In today's world, with the rapid improvement of the level of science and technology, a large number of technical terms have sprung up. In the circumstances, how to make a good deal of scientific and technological terms scientifically and accurately and be consistent with China's national conditions is a major issue, which is closely related to language development and cultural exchange. Choosing transliteration or free translation, or a combination of the two? This is the thing that linguists must carefully consider and think about when dealing with this problem. Because both of them have their own advantages and disadvantages. Relatively speaking, the former is relatively easy to operate, and is mainly to pay much attention to the choice of words of neutral words if possible. But the problem is that transliterated words are not easy for us to understand literally. So Chinese does not like borrowing the sound of words in this regard, when absorbing loanwords, and it often uses its own morphemes to reprocess and form them. For example, telephone, E-mail, microphone and others were originally transliterated into "德律风" (de lv feng), "伊妹儿"(yi meir) and"麦克风"(mai ke feng), and then translated into "电话"(dian hua), "电子邮件 "(dian zi you jian) and "扩音器"(kuo yin qi) by liberal translation. By comparison, we can see that "one syllable and one meaning" is the characteristic of Chinese, while many syllables are the features of English. The Chinese words of free translation created by Chinese language materials and wordformation methods have no substantive relationship with the original English words, pursuing 
comprehension of the meaning without requirements in phonetics basically. Similarly, the translation of ink is "墨水"(mo shui), which is done in the same way.

2) Handling of common sayings in daily life: Based on the universal law of language development, language planning aims to fix the qualified achievements of language and promotes them to serve people's communication better by the means of determining the universal standards of pronunciation, grammar and vocabulary.[5] And for those that do not conform to the law of language development, we need to standardize their usage. But in our daily communication, we often hear such words as "打扫卫生" (da sao wei sheng) and "晒太阳" (shai tai yang). According to the rules of Chinese grammar, these sayings are obviously illogical. In this case, one might say that abolishing these expressions would solve the problem. The problem, however, is that these expressions are generally accepted by the general public. It is difficult to abolish or ban them. Because people are used to these sayings, they don't think about whether or not they are logical at all. For example, "老差成怒" (lao xiu cheng nu) and "恼羞成怒" (nao xiu cheng nu) appear simultaneously in The Contemporary Chinese Dictionary, the reason is that " $n$ " and "l" are interchangeable in many dialects of China. "恼 "(nao) is often miswritten as "老"(lao). And "老差成 怒" (lao xiu cheng nu) occurs more often, which becomes habitual and is gradually accepted by the public. With regard to the particular situations, we might as well affirm and recognize the legitimacy of them according to the principle established by usage, and let them continue to serve for our daily communication. As for those new words and expressions that are not widely used by the masses and do not conform to the general rules of language development, they should be standardized or eliminated in a timely manner when they are in bud, so as to ensure the healthy and orderly development of language.

3) Dealing with new words: In recent years, a large number of new words such as "number words", "letter words" and "homophonic words" have mushroomed with the popularity of the Internet and smart phones. For example, "1314"(love you forever), "88" (bye-bye), "GG"(elder brother), "MM"(beauty), " 童 鞋 "(classmate), "大虾"(warrior), "稀饭" (like), "东东 "(thing), "菜鸟"(green hand), "斑竹"(webmaster) and so on. New words are the direct reflection of new things and new concepts, and the emergence of them enrich and develop traditional language. There are many different opinions about whether these linguistic phenomena should be regulated in the society. The relevant government departments and linguists should pay more attention to how to set standards for the use of these new words and phrases.

4) Tips on language planning: Due to the development of language, the work of language specification is impossible and unrealistic once and for all. New usages and phenomena of language emerge in endlessly in the process. In return, the specifications and standards of our language should be adjusted and revised. There should be a "dynamic synchronization" between the norms and standards of language and the language phenomena in the real world. At this point, on the one hand, we should emphasize the standardization of language. On the other hand, we should also identify reasonable elements in the process, so as to enrich our language. Because we emphasize the standardization of language, the purpose of which is to promote the development of language on the normal track, without constraining or restricting the development of language. At the same time, standardization is not simplification and modeling of the language. Standardization should also reflect the style and innovation. That is to say, standardization only eliminates the useless, uncivilized and unhealthy elements of language, and retains those elements with different rhetorical features in different styles.

\section{PROMOTION OF MANDARIN AND LANGUAGE PROTECTION}

Law on the Standard Spoken and Written Chinese Language of the People's Republic of China stipulates that Mandarin and standard Chinese characters are the common spoken and written languages of China. It confirms the social communicative status of Mandarin and standard Chinese in the form of law in China. It sets the standard of Mandarin from three aspects: pronunciation, vocabulary and grammar, taking Beijing dialect as the standard pronunciation, the northern dialect as the basic dialect, and the modern vernacular Chinese works as the grammatical norms. Taking Beijing dialect as the standard pronunciation means that Mandarin takes the phonetic system of Beijing dialect as the standard, which does not absorb all Beijing dialects. Mandarin is not equal to Beijing dialect. Based on the northern dialect, it refers to the language generally used in the vast areas of the northern dialect as the basis, but also absorb the vocabularies needed from other dialect areas of China.

China is a multi-ethnic country. The language difference between each other is very big due to its 
vast territory. Therefore, multiple dialects are a distinctive feature of China. For facilitating communication and cooperation among ethnic groups and regions better, the state has made great efforts to promote and popularize Mandarin. It is of great practical and long-term significance. First, the promotion of Mandarin can effectively enhance exchanges and cooperation among ethnic regions, preserve national unity, and strengthen the centripetal force and cohesion of the Chinese nation. Second, it is conducive to overcoming the barriers and estrangement of language, promoting political, economic and cultural constructions among regions, and accelerating their developments.

One might argue that the promotion of Mandarin is inconsistent with the dialect. The author believes that we place great emphasis on language protection in the process of the promotion and popularization of Mandarin, and they complement each other. Language protection won't affect the work of the promotion of Mandarin. On the one hand, some rules of dialects can be concluded with the help of investigating and sorting out dialects and comparing the similarities and differences between dialects and Mandarin, which is conducive to facilitating the speed of the promotion of Mandarin. On the other hand, the comparative study can effectively improve the professional level of Mandarin teachers simultaneously. I have to point out here is that to promote and popularize Mandarin does not mean banning or eliminating dialects or asking the whole nation to speak the same words in the same accent.[6] In the process of the promotion of Mandarin, many research fellows on language found that some dialects were on the verge of extinction. Meanwhile, they also found many laws of language evolution. These discoveries are of great value to the ecological protection of language. At present, the work of the investigation and research on the rescue of some endangered languages and dialects are being carried out in full blast.

\section{CONCLUSION}

Language is not only the most important form of human culture, but also the basic form embodying the value of human life. In a sense, language is not only a social phenomenon but a mirror reflecting its distinctive national characteristics. The essential diversity of human language reflects the complexity of language. Therefore, we should put it in a big linguistic field of vision, and make an integrated comprehensive investigation, from macro to micro as well as from the synchrony to diachronic. Only in this way can we really grasp its essence.

\section{References}

[1] Stalin, Complete Works of Stalin, vol. 2. Beijing: People's Publishing House, 1953, pp.294.

[2] Kachru, B.B. The Alchemy of English: The Spread, Functions and Models of Non-Native English. Oxford: Pergamon, 1986, pp.5.

[3] Harrison, G. Political Identities and Social Struggles in Africa. In A.J.Kershen (ed.) A Question of Identity. Aldershot: Ashgate, 1998, pp.248.

[4] Guo Xi, Chinese Sociolinguistics. Zhejiang: Zhejiang University Press, 2004, pp.270.

[5] Ye Feisheng, Xu Tongqiang. An Outline of Linguistics. Beijing: Peking University Press, 2009, pp.189.

[6] Zhou Enlai,The Task of the Current Character Reform, vol.1. Beijing: Language Construction, 1982, pp.35. 